\title{
As três acepções fundamentais da palavra Direito $(*)$
}

Miguel Reale

A filosofia do Direito coloca-nos em face da necessidade de discriminar, preliminarmente, algumas das acepções fundamentais da palavra "Direito". Nas ciências chamadas exatas, os vocábulos têm, em regra, um significado bastante preciso; um físico ou um químico jogam com um vocabulário próprio e o fazem com certa garantia de que dada palavra traduz, sempre, um significado constante e comum entre os cultores das respectivas ciências.

Nas ciências culturais, essa precisão terminológica é dificil, quando não impossível.

A vacilação do significado dos termos resulta da diferença mesma existente entre as ciências físico-matemáticas e as ciências que chamamos culturais, ou "ciências do espírito". Naquelas o observador coloca-se diante de um objeto, procurando alcançar a máxima neutralidade, de maneira que o seu coeficiente pessoal não possa perturbar o resultado da pesquisa.

O cientista de laboratório pretende adquirir um gráu extremo da despersonalização, de modo que o fenômeno em exame seja apreendido tal como êle é. Há dois elementos fundamentais nessa análise científico-positiva: de tum lado, a possibilidade de uma crescente despersonalização do observador e, de outro, a estabilidade do objeto

(*) Este artigo corresponde a uma das aulas do curso de Filosofia do Direito, em 1949, conforme notas taquigráficas revistas. 
da própria pesquiza. Os elementos formadores do mundo material, embora não se comparem com os do mundo matemático, são estaveis; se provoco uma reação com determinados líquidos, tenho a certeza de que, mantidas iguais condições, êles reagirão sempre da mesma maneira. Isso não acontece no mundo das criações humanas, pois o objeto de estudo do Direito, da Política, da Economia, etc., é, em última análise o homem mesmo, ou seja, um ser livre, que muda continuamente através do tempo, e que, com a sua liberdade, representa uma soma de imprevistos e de contingência no processo dos fatos analisados.

As ciências culturais, em contraposição á exatidão e á certeza das ciências chamadas positivas, apresentam duas características: menor possibilidade de despersonalização por parte do cientista, e a mutabilidade nos elementos sob análise. Se existem tais diferenças é claro que se apresente também uma variação de terminologia, que não encontramos no campo físico-matemático. Daí dizer-se que nas ciências culturais pode haver "rigor", mas não exatidão de resultados.

Henry Bergson (1859-1940), um dos grandes vultos do pensamento filosófico de nosso tempo, afirmou que as palavras são prisões dentro das quais se contêm idéias, que se transformam, que vivem e se ajustam a situações diferentes. $E^{\prime}$ preciso penetrar nessas prisões, partir a estrutura gráfica das palavras, para entrar em contacto com a riquesa do conteúdo que nelas se encerra. E' o que pretendemos fazer, em linhas gerais, com a palavra, "DIREITO", palavra trabalhada por gerações e gerações através de séculos de lutas e indagações, palavra que, no fundo, se confunde com o próprio destino da espécie humana.

Desde que um homem surge, posto diante de outro homem, põe-se o Direito, como uma delimitação garantidora de atividades recíprocas. Através da história, obedecendo a idéias diversas, o homem vem realizando o Direito. vivendo regras jurídicas, em uma experiência incessante e ás vezes trágica. 
Toda história humana liga-se essencialmente á história do Direito, porque tudo quanto o homem fez, desde as grandes realizações artísticas até á mais humilde das utilizações domésticas, tudo está condicionado, direta ou indiretamente, pelo Direito ou se manifesta mediante formas juridicas.

O Direito não é tudo, mas é a condição de tudo; não é a vida, mas é a garantia predípua da vida do homem em sociedade.

Se tomarmos a palavra Direito e desdobrarmos as camadas de seu conteúdo, verificaremos que ela se apresenta com três acepções fundamentais, que assinalam 3 facetas de uma única realidade indecomponivel. A primeira acepção da palavra Direito prende-se aos primórdios da cultura e representa, na realidade, o significado primordial; é o Direito significando o "justo". Quando se nos depara uma injustiça, quando nos revolta o abuso da força, quando vemos o fraco espesinhado pelo forte, gritamos logo: "não é direito!", ou então, "está sendo violado o direito", ou ainda, "o direito exige que se faça uma reparação". E' ainda, nesse sentido, que se proclamam as guerras e as lutas cívicas em defeza do "Direito".

E' o significado do Direito como "justo", como um ideal que sobrepaira ás contingências de espaço e de tempo.

A primeira noção que os grandes pensadores tiveram do Direito, foi como "Justiça". Não foi com Socrates (470-399 AC) nem Piatão (427-248 AC) ou Aristóteles (384-322 $\mathrm{AC}$ ), que os homens começaram a agitar o problema; desde as primitivas teogonias, ou seja, desde aquelas elocubrações ao mesmo tempo religiosas e filosóficas, que surgiram como concepção total do universo e da vida, encontramos o sentido de Direito como justiça.

São antigas na história do pensamento humano perguntas como estas: "Que é justo?" "Existe o justo por natureza, ou o justo representa méra convenção"? - "0 justo se confunde com o ordenado por lei?" - "Será o justo a vontade do mais forte, ou será, ao contrário, algo 
que se deva impor também aos mais fortes?". O problema do justo remonta, por assim dizer, ás raizes das pesquizas humanas. Só mais tarde é que o Direito como sistema positivo de normas passa a ser objeto de cogitações de uma ciência autônoma. Cronològica e filosòficamente falando, ou seja, do ponto de vista histórico e lógico, o problema básico é o do Direito como justo.

Essa preocupação de alcançar a justiça, êsse desejo ardente que a espécie humana alimenta de realizar a igualdade e a harmonia dos interêsses, através dos tempos, dá lugar a uma experiência social, a uma forma de conduta, a um modo de ser e de comportar-se que nós denominamos "experiência jurídica".

o Direito é uma experiência vital; é uma soma d€ atos que as gerações vão vivendo, uma após outras, dominadas, todas, pelo ideal que chamamos do justo. Pois bem, a esta experiência histórica, que se concretiza no tempo, ao fato social que progride ou regride assumindo fisionomias e aspectos diversos, variando de lugar para lugar, de tempo para tempo, e exprimindo-se em sistemas de normas positivas também damos o nome de Direito.

Vejam bem: em primeiro lugar, o Direito é percebido como justo, ou seja, como um sistema de valores subordinado ao valor de Justiça, valor que consiste em servir aos demais valores na coexistência social, pois é próprio do Direito criar as condições indispensaveis para que indivíduos e grupos possam realizar plenamente suas aspirações ou tendências no sentido do bem, do belo, do útil, do verdadeiro ou do santo.

Em segundo lugar, tem-se o Direito como forma mais concreta, como fato social, como " a objetivação do justo no tempo", o que equivale a ver o Direito Positivo como uma realidade posta pelo Espírito, uma objetivação do Espírito no sentido intencional do valor do justo. 
Mas, não se para aí. O homem não faz apenas regras de conduta; tão pouco se limita a obedecê-las ou a desrespeitá-las. Em certo momento da evolução cultural, surge a necessidade de se estudar a experiência jurídica, de examinar o mundo complexo das regras, buscando-se entre elas uma constante, a razão de sua unidade, os laços de subordinação recíproca, os motivos de sua composição em um todo lógico coerente.

Tal fenômeno de compreensão unitária, de sistemática da realidade histórico-social, verifica-se quando surge a Ciĉncia do Direito. Esta aparece milênios após o início da experiência jurídica, cujo estudo em si (a Sociologia Jurídica) é ainda mais recente.

Foram os romanos que, não se limitando a viver o Direito, quizeram compreende-lo, na sua unidade sistemática e lógica.

A ciência só surge quando há unificação e sistematização. O primeiro povo a se preocupar com a coordenação lógica das regras jurídicas, com a distribuição dos preceitos em institutos, dêstes em sistemas particulares e dêstes dinua em sistemas gerais, á luz de principios diretores, foi o povo romano.

Temos, assim, a terceira acepção da palavra Direito: o Direito como ciência, ou seja, como compreensão racional, unitária e lógica, do fato social que denominamos também Direito.

Estão vendo, portanto, que a palavra Direito designa trĉs coisas distintas mas que, efetivamente, não são senão três aspectos distintos da mesma realidade, três facetas do mesmo objeto, ou se quizerem, três momentos distintos da objetivação do Espírito.

Do exposto resulta o quadro gráfico que podemos estabelecer, discriminando no Direito as três faces com as quais se compõe a pirâmide jurídica: 


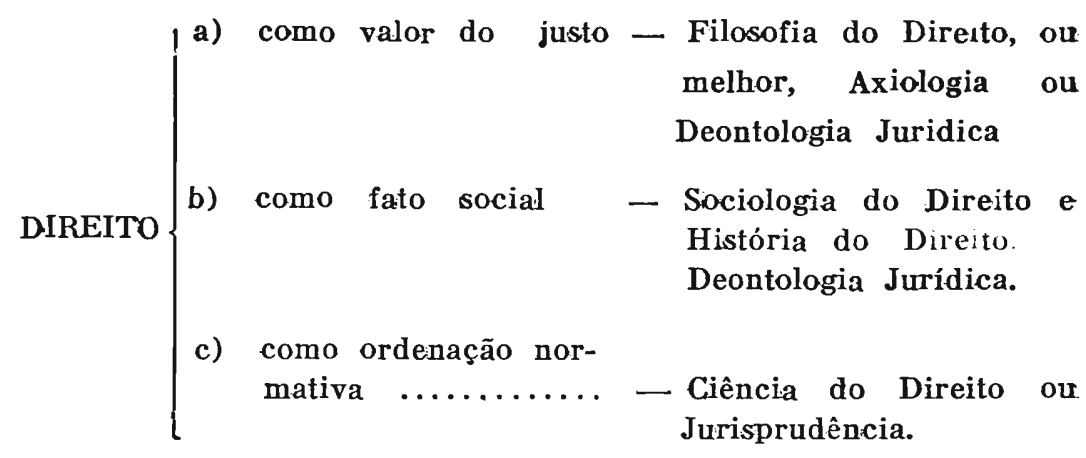

O estudo do Direito como justo é feito pela Filosofia do Direito. Alguns mestres chegam, mesmo, a dizer que Filosofia do Direito é apenas o estudo crítico-sistemático do justo, declarando que todos os demais são estudo acessórios. Para nós, o problema do justo não é apenas um problema ético ou moral. O problema do justo implica em condições lógicas e éticas. Como a Filosofia do Direito, além do justo, estuda os pressupostos da Ciência do vireito e da experiência juridica concreta, podemos adiantar esta noção: "Filosofia do Direito é a Filosofia mesma enquanto determina as condições lógicas e éticas do justo e de sua objetivaçãu no plano histórico-cultural."

Esta noção demonstra que a Filosofia do Direito governa, como cúpola do sistema, a totalidade das regras jurídicas, uma vez que fixa os princípios lógicos e éticos que condicionam a atividade científica dos juristas, determinando um tipo especial de conduta social que se caracteriza por ser bilateral atributiva, razão de ser de sua coercibilidade.

Passando ao exame do segundo prisma, encontramos o fato social que, com mais precisão, denominamos "fato histórico-cultural".

Pois bem, duas ordens de pesquizas se destinam ao exame do fato jurídico: uma é a Sociologia do Direito; a História do Direito a outra. 
Sé o Direito é um fato social que se desenrola no tempo, variando de país para país, de época para época, é suscetível de ser estudado pelo historiador. Há uma história do Direito, como há uma história particular de cada uma de suas instituições; podemos estudar, por exemplo, o matrimônio ou a propriedade através dos tempos. Os problemas de História do Direito põem em vista, evidentemente, outro problema complementar que é o da Filosofia da História do Direito.

A Sociologia do Direito distingue-se da História do Direito, porque esta estuda o desenvolvimento e a concatenação dos fatos em sua singularidade, ou seja, com todas as suas características de elementos individuais, muito embora o deva integrar no fluxo geral dos acontecimentos, buscando-lhe o sentido perene.

Diversa é, porém, a finalidade da Sociologia do Direito que estuda os fatos na sua generalidade. E' claro que a Sociologia também está condicionada pelo espaço e pelo tempo, mas, a preocupação do sociólogo não é um fato que tenha acontecido, "hic et nunc", mas sim, as condições ou as causas geradoras do acontecimento, bem como seus nexos com os demais elementos ou fatores sociais.

Para o historiador um fato particular tem um significado extraordinário. O nascimento de Napoleão é um fato histórico que revoluciona todo o desenvolvimento político-cultural da espécie humana; entretanto, o fato do nascimento de Napoleão não interessa ao sociólogo senão como dado ou élo de um sistema, sucetível de ser considerado em gráu de generalidade.

Em suma, o fato histórico particular ou geral é sempre estudado, tanto pela História do Direito como pela Sociologia do Direito, mas com diverso entendimento, embora entre ambas existam relações íntimas. Não há em verdade grande sociólogo que não seja dotado de grande lastro de conhecimentos históricos, e vice-versa.

Podemos dizer que a história representa a laboratório de experiência do sociólogo. Como não podemos provocar 
acontecimentos sociais, como faz o físico ou o químico, outra coisa não nos resta senão voltar os olhos para o passado, observando as experiências de outras gerações e tirando conclusões para os nossos tempos.

Visto, assim, o Direito como experiência histórica, passemos a considerá-lo como "estrutura normativa", ou seja como processo ou técnica de pensamento, como compreensão racional.

Então surge outro campo de pesquizas, outra ordem de indagações - é a Ciência de Direito, ou Jurisprudência. Nesta Faculdade, não estudamos de preferência o Direito como fato social em si, mas sim em "referibilidade normativa", isto é como conjunto de princípios ou de conceitos, pelos quais se ordenam e se compreendem certas regras sociais dotadas de garantias específicas. Costumamos dar a essa parte do Direito o nome tradicional de "jurisprudência", que se desdobra em múltiplos aspectos, como sejam o Direito Civil, o Direito Comercial, o Direito Penal etc.

Como, porém, o Direito não pode ser separado dos demais fatores, que compõem o processo cultural, nas Faculdades de Direito estudam-se disciplinas que não são, propriamente, jurídicas, mas que iluminam a visão dos fatos jurídicos; entre elas, podemos citar a Economia Política, a Ciência das Finanças, a Teoria do Estado, a Criminologia, e a Medicina Legal.

Estão vendo os senhores que, pela propria análise da palavra Direito, desdobrada na riquesa dos seus significados, temos o programa daquilo que nos cumpre estudar durante êste ano. Fazendo o estudo do justo, do fato social com referência ao justo, dos processos lógicos da ciência jurídica também com relação ao justo, o que nos cabe ponderar, de princípio, é que não pretendemos jamais partir sua unidade, nem fazer prevalecer um dos seus aspectos sôbre os outros, porquanto o Direito não é outra coisa senão o Espírito como intersubjetividade.

Mesmo em nossa época, encontramos autores que, dando demasiada importância a um deterininado aspecto ou ob- 
servando as questões segundo determinado ângulo, pretendem subordinar-lhe todos os demais.

Sociologos há, com efeito, que querem reduzir a F1losofia do Direito ou as Jurisprudências a um capitulo da Sociologia Juridica. Acham que sociológicas deveriam ser, por exemplo, a interpretação e a aplicação do Direito pelos juizes, assim como a elaboração das leis, e toda a sistemática da ciência jurídica.

Por outro lado, não faltam juristas que, colocados exclusivamente no plano filosófico, pretendem integrar na Filosofia do Direito todas as expressões do mundo jurídico, transformando a jurisprudência em méra arte de aplicação de dados preceitos de ordem ética.

Há, finalmente, aqueles que se colocam estritamente no plano do Direito Positivo, entendendo-o como sistema lógico de normas auto-suficientes, e, encarando o Direito tão sòmente quanto ao seu aspecto lógico ou técnico, desconhecendo por completo o aspecto sociológico ou filosófico do problema. São aqueles para os quais a Ciência do Direito seria uma Enciclopédia Jurídica, a qual dispensaria a própria Filosofia do Direito. Durante muito tempo, esta visão positivista e acanhada dominou os espíritos; a tal ponto que, nesta mesma Faculdade, deixou de ser lecionada Filosofia do Direito, para ser estudada apenas Enciclopédia Jurídica. Apareceu, em seguida, a reação natural e justa contra essa visão unilateral da vida jurídica, afim de se estabelecer o equilíbrio das três facetas, evitando a elefantiase de um aspecto, tendente a absorver os outros, e recompondo-se a harmonia do sistema.

Isto demonstra que refugimos das concepções unilaterais da vida jurídica; temos, mesmo, tentado lançar as bases de uma concepção que se poderia chamar de "concepção tridimensional do Direito", incompativel ao mesmo tempo, com as visões unilaterais do sociologismo, do eticismo e do normativismo puros.

Para essa concepção tridimensional do Direito, a realidade jurídica se apresenta como uma realidade comple- 
xa, que se integra de três elementos: fato, valor e norma. Só mais tarde poderão os senhores compreender toda a riqueza dessas palavras. Por enquanto, são méras noções que demonstram como, através da análise do termo, do vocábulo Direito, vamos arrancando dele, sucessivamente, os elementos que nos permitirão uma sondagem nas raizes do problema basilar que nos preocupa.

Em resumo, a realidade jurídica é uma realidade complexa, que reune em sí três elementos complementares, de maneira absolutamente necessária. Podemos mesmo dizer que a experiência jurídica, o fato social, vai se integrando cada vez mais na estrutura lógico-normativa da Ciência do Direito, afim de alcançarmos as condições ideais do que consideramos justo. Há uma perfeita entrosagem no processo histórico, porquanto o homem aperfeiçoa a Ciência do Direito para apreender o fato social no sentido autêntico do justo.

O estudo dos senhores tem sido dirigido no sentido da Ciência do Direito; estudaram jurisprudências, como o Direito Civil, o Direito Penal, e, assim por diante; receberam o Direito na sua estrutura lógico-compreensiva de regras de conduta. Cumpre, agora, verificar que as regras jurídicas não surgiram por acaso, nem por um capricho do legislador, mas que, ao contrário, representam a expressão lógica de uma realidade subjacente, á qual se ligam fenômenos econômicos, geográficos, demográficos, artísticos, éticos, religiosos etc. e que tal expressão lógica tem, como finalidade ínica, a realização dos valores do justo.

O Direito desenvolve-se, por conseguinte, como a própria vida humana na sua expressão de co-existência pacífica e livre. Enquanto o homem se concentra em si mesmo e vive como homem isolado, não há que falar em Direito. o Direito surge tão sòmente quando um homem se coloca diante de outro homem e há recíproca afirmação do "eu". Se ambos dizem "eu sou", surge o problema da existência 
do "outro", que só se resolve plenamente pela afirmação: "nós somos".

Esta já é a afirmação do Direito mesmo, porque pelo Direito se torna possível a co-existência pacífica e ordenada de indivíduos e de grupos, distintos segundo sua livre razão comum de ser. Igualdade de homens livres em uma convivência feita de recíproco respeito e de concordia.

Não há, pois, que separar a Filosofia do Direito da Sociologia ou da História do Direito. São pesquizas que se conjugam e se coordenam, distinguindo-se apenas por um esforço de abstração, por necessidades lógicas e pedagógicas, mas que devem, depois, ser reconduzidas em síntese, no momento da atividade prática da aplicação do Direito, de sua integração como momento da vida.

Os grandes jurisconsultos, da família de BevilacQua (1833-1946), de Teixeira de Freitas (1817-1883), de Lafaiete (1734-1917), jamais ficaram ilhados no exclusivismo da técnica jurídica.

Sabiam aliar a ciência do justo á do fato social e histórico, porque viam o Direito em sua totalidade, multiplicando-se em facetas, arestas, ângulos e perspecticas, como partes sempre ligadas umas às outras na harmonia de um tôdo orgânico. 